\title{
The reliability of the nonradiologic measures of thoracic spine rotation in healthy adults
}

\author{
Donggi Hwang ${ }^{a}$, Ju Hyeong Lee ${ }^{a}$, Seongyeon Moon ${ }^{a}$, Soon Woo Park ${ }^{a}$, Juha Woo ${ }^{a}$, Cheong Kim ${ }^{b}$ \\ ${ }^{a}$ Department of Physical Therapy, College of Health Science and Social Welfare, Sahmyook University, Seoul, Republic of Korea \\ ${ }^{b}$ Department of Health Management, College of Health Science and Social Welfare, Sahmyook University, Seoul, Republic of Korea
}

\begin{abstract}
Objective: The purpose of this study was to examine the intertester reliability and validity of four nonradiologic measurements of thoracic spine rotation in healthy adults.

Design: Descriptive laboratory study.

Methods: This study was conducted on 20 male and 20 female university students aged between 19 and 26 . To measure thoracic rotation, a goniometer, a bubble inclinometer, a dual inclinometer, and a smartphone application-clinometer were used. The measurement was performed twice for each device and the same measurement was performed by two examiners. The measurements were performed in the lumbar locked position. The arm in the direction of rotation was taken back and placed onto the back of the lumbar region. With right and left trunk rotation, the head was rotated together but remained in the center line so that the axial rotation was maintained. Both examiners performed the measuring procedures and directly handled the measuring instrument. All measurement results were recorded by the recorder.
\end{abstract}

Results: The range of motion (ROM) of thoracic rotation in lumbar locked position for all four devices was 47 degrees. The intra-rater reliability estimates ranged from 0.738 to $0.906(p<0.05)$. The inter-rater reliability estimates ranged from 0.736 to 0.853 $(p<0.05)$. The goniometer, bubble inclinometer, dual inclinometer, and smartphone clinometer showed high validity $(p<0.05)$. This result indicates that all four devices may be used by the same examiner and by other examiners obtaining follow-up measurement.

Conclusions: The use of the goniometer, bubble inclinometer, dual inclinometer, and smartphone clinometer for measurements in the lumbar locked posture are reliable and valid nonradiologic measures of thoracic rotational ROM in healthy adults.

Key Words: Measure, Range of motion, Rotation, Thoracic vertebrae

\section{Introduction}

Spine rotation has long been a critical part of clinical interest and it is an important components of movement assessment [1-3]. Many authors have found significant effects of thoracic position on different parts of the body including the neck and scapula. The pain and range of motion (ROM) changes in the cervical spine could be a result of intervention on the thoracic spine $[4,5]$. Clinically, many findings suggest that when assessing and applying therapeutic move- ment techniques on the thoracic spine, a therapist should consider the ipsilateral coupling of lateral flexion and rotation $[3,6,7]$. It is important to measure relevant thoracic spine range of movement measurement during physical therapy assessment and applying movement techniques [8].

The normative measurement of cervical and lumbar spine ROM has been published but no actual standardized angle for thoracic rotation has been published $[9,10]$. There was a study related to thoracic measurement but it showed variable result between subjects and dependant on the thoracic re-

Received: 17 May, 2017 Revised: 14 June, 2017 Accepted: 14 June, 2017

Corresponding author: Cheong Kim

Department of Physical Therapy, College of Health Science and Social Welfare, Sahmyook University, 815 Hwarang-ro, Nowon-gu, Seoul 01795, Republic of Korea

Tel: 82-2-3399-1911 E-mail: ckim@syu.ac.kr

(c) This is an Open-Access article distributed under the terms of the Creative Commons Attribution Non-Commercial License (http://creativecommons.org/licens es/by-nc/4.0) which permits unrestricted non-commercial use, distribution, and reproduction in any medium, provided the original work is properly cited.

Copyright $\odot 2017$ Korean Academy of Physical Therapy Rehabilitation Science 
gions [8]. In selective functional movement assessment (SFMA) evaluation process, the thoracic spine is considered a mobile segment where flexion, extension, lateral flexion, and rotational movements occur [11]. In SFMA breakout test, trunk rotation is measured in two positions. The first measurement is performed in seated position and the second measurement posture is in lumbar locked position $[12,13]$. To consider if a thoracic rotation movement is functional, the torso rotation range measured in seated position and lumbar locked position should be 50 degrees or greater. It is considered dysfunctional if the measurement value is not over 50 degrees [14]. However, the validity of this thoracic rotation of 50 degrees criterion has not been proven to date.

There are different methods for measuring thoracic spine rotational ROM and many researchers suggested that the seated torso rotation test and lumbar-locked torso rotation tests may be used reliably for this measurement [15]. The ROM of thoracic spine rotation is affected by the posture from which the movement is performed [16]. The movement pattern of each person is different and the shape of the spine and muscular control are two main factors for the rotation movement [17]. There is another reason for adopting lumbar locked position as the only posture for the thoracic measurement in this research. In seated position, there are devices that cannot be used due to the nature of the electronic sensors when measuring ROM. The torso rotation motion is performed in the horizontal plane during the seated rotation test and performed in the sagittal plane during the lumbar locked test. In the lumbar locked rotation test, most of the electronic devices could be used due to the motion is in sagittal plane. In this research, we will be looking at the thoracic rotation measurement in lumbar locked position.

It is important that a clinician should use standardized methods during the ROM test [18]. Some research studies suggest that the result of the different measuring devices cannot be used reliably [19]. A variety of instruments such as $\mathrm{x}$-ray, motion analyzer, goniometer, inclinometer, smartphone application, and dual inclinometer are used to measure the angle of spinal rotation [20-22]. The most frequently used devices in clinical practice are goniometer and there are many studies has been published on using other devices including smartphone application for ROM in different body parts $[23,24]$. However, the study on validity and reliability of the goniometer, bubble inclinometer, dual inclinometer, and smartphone application clinometer for thoracic rotation has not been published. The purpose of this study is to measure the accurate angle of thoracic rotation and to determine which measurement device is the most reliable among the four commonly used by the therapist and to suggest most reliable and convenient way to measure thoracic ROM.

\section{Methods}

\section{Subjects}

This study was conducted on 20 males and 20 females students who are currently enrolled in the University. The study subjects were selected from those who voluntarily participated the experiment. Subjects with condition of rheumatic disease, pain, congenital or acquired disease around the thoracic spine (vertebrae, knee joints, shoulder joints, ribs, etc.) and in the pregnant women were excluded from the study.

\section{Instruments}

A goniometer, a bubble inclinometer, a dual inclinometer, and a smartphone application-clinometer were used and the subject's thoracic rotational ROM of the spine was measured in the lumbar locked position. After all the result was collected, the reliability of each instrument, the inter-instrument reliability, and the validity of each instrument were calculated (Figure 1).

The goniometer is a tool that can measure angles from 0 to 360 degrees and is marked at intervals of 5 degrees. One of the two arm is fixed and the other arm is moved to the end-range of the movement and the final displayed ROM angle is recorded. The goniometer measurements were made by placing the stationary arm of the goniometer on the $\mathrm{T} 1$, $\mathrm{T} 2$ (spine of scapula) or T1 and T2 junctions of the subject parallel to the imaginary line connecting the two shoulders, and the mobile arm was aligned parallel to the floor (Figure 2A).

The bubble inclinometer was placed at the baseline of the

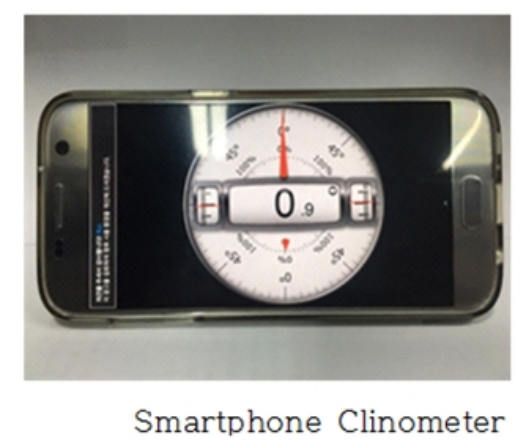

Figure 1. Measurement devices. 


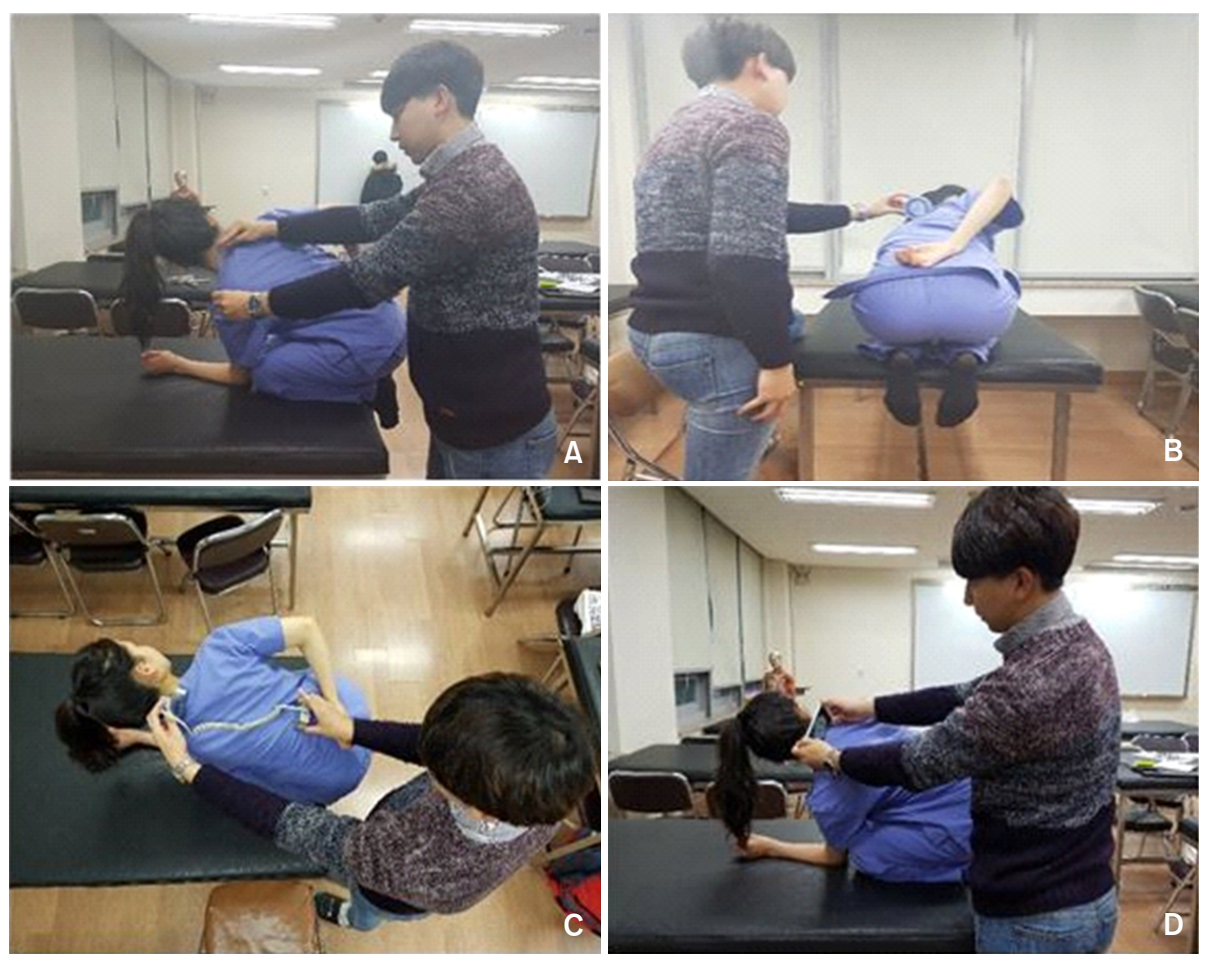

Figure 2. Measurement procedure. (A) Goniometer measurement. (B) Bubble inclinometer measurement. (C) Dual inclinometer measurement. (D) Smartphone clinometer measurement. subject's body where the ROM to be measured. Then the dial was turn until the scale reads 0 . After the rotational motion is performed through its range, the angle was measured directly from dial (Figure 2B).

The dual inclinometer is used for the thoracic rotational ROM in lumbar locked position. The examiner measures functional ROM through opposing joint motions using a common neutral zero point. The dual inclinometer is initially calibrated with the two sensors horizontally aligned, and the zero mark is initialized. The skin mark is then attached to the subject's T1 and T12 spinous processes and the subject are instructed to get in the lumbar locked position until the vertebrae is bent forward to end-range and it is level on the floor. The primary sensor was placed to $\mathrm{T} 1 \mathrm{of}$ transverse plane and secondary sensor to T12. The two sensors must be perpendicular to the floor in the starting position (Figure 2C).

The smartphone clinometer is an application that can measure the ROM by its inclination in any direction. Some differences may be found depending on the type of application or the smartphone equipment. The smartphone is placed parallel with the joint to be measured and the phone displays the angle of inclination. The measurement of the smartphone clinometer is performed by positioning the probe at the $\mathrm{T} 1$ and $\mathrm{T} 2$ spinous process (T1 and $\mathrm{T} 2$ ) or $\mathrm{T} 1$ and $\mathrm{T} 2$ junctions as it was applied in the goniometer measurement
(Figure 2D).

\section{Procedure}

The measurement for the thoracic rotational ROM is carried out twice in total per device and the measurement order is randomly selected. The two examiner measures the ROM from the left side rotation and then measures the right side. The examiner A first measures the ROM with four instruments and then the examiner B performs the measurement in the same procedure.

The measurement is performed in the lumbar locked position and the starting and ending posture of the movement is as shown (Figure 3). The hips are rocked back to the ankle as much as possible and the posture is maintained during the measurement. The elbow and forearm is placed on the floor in the midline with the elbows right in front of the knees. The arm in the direction of rotation is taken back and placed to the back of the lumbar region. When the trunk is rotated, the head can rotate together but the head should remain in the center line so that the axial rotation is maintained.

There were two examiners (examiners A and B) and one recorder. Both examiners carry out the measuring procedure and handles the measuring instrument directly, but the measurement result is recorded only by the recorder. The examiner measures the ROM of the thoracic spine rotation in each of the left and right side of the subjects twice. Four measur- 


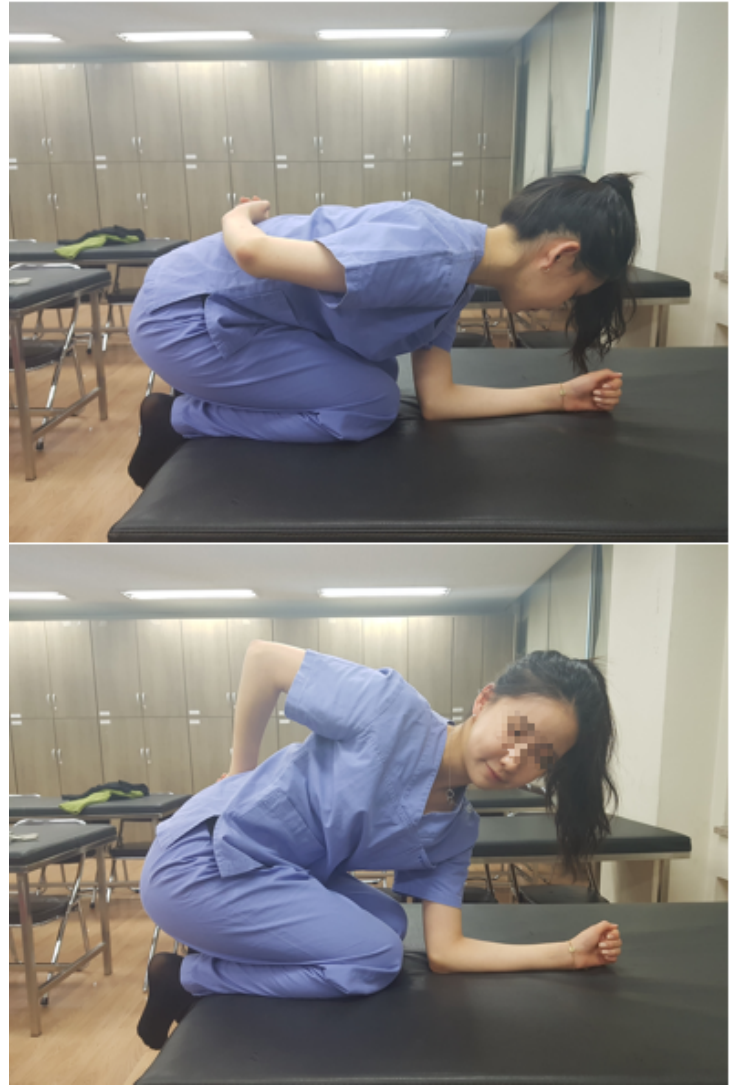

Figure 3. Lumbar locked thoracic rotation position.

Table 1. Mean value of measurement by device

$(\mathrm{N}=40)$

\begin{tabular}{lccc}
\hline \multicolumn{1}{c}{ Measurement } & Minimum & Maximum & Mean (SD) \\
\hline Goniometer & 39.88 & 54.00 & $46.55(2.71)$ \\
Bubble inclinometer & 39.13 & 53.00 & $46.65(2.53)$ \\
Dual inclinometer & 41.00 & 53.38 & $46.79(2.64)$ \\
Smartphone clinometer & 39.63 & 54.50 & $46.89(2.85)$ \\
\hline
\end{tabular}

ing instruments were used at the same procedure (goniometer, bubble inclinometer, dual inclinometer, and smartphone clinometer).

\section{Results}

The mean value and standard deviation of thoracic spine rotation for each of four measuring devices on the thoracic spinal rotation ROM is presented. The mean values of the instrumental measurements were $46.55 \pm 2.71$ in the goniometer, $46.65 \pm 2.53$ in the bubble inclinometer, $46.79 \pm 2.64$ in the dual inclinometer and $46.89 \pm 2.85$ in the smartphone clinometer. The measurement with the goniometer had the lowest ROM (46.55) and the smartphone clinometer had the
Table 2. Intra-rater reliability

\begin{tabular}{lccc}
\hline \multicolumn{1}{c}{ Variable } & ICC & $95 \%$ CI & $p$ \\
\hline $\begin{array}{l}\text { Goniometer } \\
\text { Right }\end{array}$ & 0.738 & $0.505-0.861$ & $<0.001$ \\
$\quad$ Left & 0.834 & $0.686-0.912$ & $<0.001$ \\
Bubble inclinometer & & & \\
$\quad$ Right & 0.777 & $0.579-0.882$ & $<0.001$ \\
$\quad$ Left & 0.819 & $0.659-0.904$ & $<0.001$ \\
Dual inclinometer & & & \\
$\quad$ Right & 0.906 & $0.822-0.950$ & $<0.001$ \\
$\quad$ Left & 0.824 & $0.667-0.907$ & $<0.001$ \\
Smartphone clinometer & & & \\
$\quad$ Right & 0.896 & $0.803-0.945$ & $<0.001$ \\
$\quad$ Left & 0.829 & $0.676-0.909$ & $<0.001$ \\
\hline
\end{tabular}

ICC: intra-class correlation coefficient, CI: confidence interval.

highest number (46.89). The average of the thoracic rotational ROM in the lumbar locked position for all four devices was 47 degrees (Table 1).

\section{Intra-rater reliability}

The intra-rater reliability estimates ranged from 0.738 to $0.906(p<0.001)$. The significanct value of the intra-rater reliability for all four devices was 0.000 for both right and left sides. The intra-rater reliability of both dual inclinometer and smartphone clinometer was higher than the other two other devices (Table 2). The reliability value for goniometer was the flowest among four devices.

\section{Inter-rater reliability}

The inter-rater reliability estimates ranged from 0.736 to 0.853 . The significance value of the inter-rater reliability for all four devices was $<0.001$ for both right and left side. The value for goniometer was highest among four devices. The lowest value was also found in the goniometer among four measurement devices. It is interesting that the highest and the lowest value was seen in the goniometer. The inter-rater reliability of smartphone clinometer was second highest among four measurement devices (Table 3). This result indicates that all four devices may be used for the same examiner and for other examiners obtaining follow-up measurement.

The validity of the measurement was assessed reviewing the correlation between the four instruments. The Pearson's correlation coefficient between the devices are as following: Goniometer inclinometer-Bubble inclinometer 0.840 $(p<0.001)$, Goniometer inclinometer-Dual inclinometer 
$0.848(p<0.001)$, Goniometer inclinometer-Smartphone clinometer $0.886(p<0.001)$. Higher relationship is noted in Bubble inclinometer- Dual inclinometer $0.943(p<0.001)$, Bubble inclinometer- Smartphone clinometer 0.954 ( $p<$ 0.001 ), and Dual inclinometer-Smartphone clinometer 0.946 $(p<0.001)$. This suggest that all four devices can be used to measure thoracic rotational ROM and any of the four devices will result in similar result (Table 4).

\section{Discussion}

The purpose of this study was to determine the reliability of four devices in measuring thoracic rotational ROM in lumbar locked position. The value of thoracic rotation is at 47 degrees which is similar to the other studies, but further study is required to confirm the normal value for this measurement [15]. From the result of this study, the thoracic rotation in lumbar locked position is 47 degrees. In SFMA, thoracic spine is considered dysfunctional if the range of measurement is below 50 degrees.

The findings in this study suggest that the four devices used for measuring thoracic rotation in lumbar locked posi-

Table 3. Inter-rater reliability

\begin{tabular}{lccc}
\hline \multicolumn{1}{c}{ Variable } & ICC & $95 \%$ CI & $p$ \\
\hline Goniometer & & & \\
$\quad$ Right & 0.853 & $0.722-0.922$ & $<0.001$ \\
$\quad$ Left & 0.736 & $0.500-0.860$ & $<0.001$ \\
Bubble inclinometer & & & \\
$\quad$ Right & 0.794 & $0.610-0.891$ & $<0.001$ \\
$\quad$ Left & 0.765 & $0.556-0.876$ & $<0.001$ \\
Dual inclinometer & & & \\
$\quad$ Right & 0.787 & $0.597-0.887$ & $<0.001$ \\
$\quad$ Left & 0.786 & $0.595-0.887$ & $<0.001$ \\
Smartphone clinometer & & & \\
$\quad$ Right & 0.803 & $0.628-0.896$ & $<0.001$ \\
$\quad$ Left & 0.825 & $0.668-0.907$ & $<0.001$ \\
\hline
\end{tabular}

ICC: intra-class correlation coefficient, CI: confidence interval. tion are reliable. All the value for intra-rater and inter-rater intra-class correlation coefficient were greater than 0.74 , and can be suggested as good. Despite of a good reliability, there were difference between the devices used by same examiner for the thoracic rotation. The values for dual inclinometer and smartphone clinometer were higher than other devices. It is consistent with finding of other studies that dual inclinometer and smartphone clinometer shows good reliability [23,24].

The lowest value was shown in the goniometer measurement. The values between the devices used by different examiners were quite different in their value. The value for goniometer was highest among four devices. This is quite similar to the result from other research studies [19]. It is interesting that the highest and the lowest values were seen in the goniometer. The highest value was the right-side trunk rotation and the lowest was in the left-side rotation.

The value for smartphone clinometer was second highest among four measurement devices. This suggest that the smartphone clinometer was most reliable method among four devices we used. The smartphone clinometer may be the best devices for measuring thoracic rotation ROM in lumbar locked position. There were many research articles questioning the reliability of the smartphone clinometer but other studies show the good reliability of the devices $[23,24]$.

For movement assessment, thoracic rotation may be a critical variable to measure to determine functional range. The most reliable posture for measuring thoracic spine rotation was bar behind seated position and lumbar locked position. Many therapists start using smartphone clinometer in measuring ROM in the clinical settings due to their preference to have digital number to the measurement and the devices are now easily accessible. The key issue for the smartphone clinometer is that the device was not applicable in certain positions such as seated position. The goniometer was applicable to both seated and lumbar locked position but most of the electronic devices were not applicable to meas-

Table 4. Pearson's correlation coefficient between four measurement tools

\begin{tabular}{lcccc}
\hline \multicolumn{1}{c}{ Variable } & Goniometer & Bubble inclinometer & Dual inclinometer & Smartphone clinometer \\
\hline Goniometer & - & $0.840^{*}$ & $0.848^{*}$ & $0.886^{*}$ \\
Bubble inclinometer & $0.840^{*}$ & - & $0.943^{*}$ & $0.954^{*}$ \\
Dual inclinometer & $0.848^{*}$ & $0.943^{*}$ & - & $0.946^{*}$ \\
Smartphone clinometer & $0.886^{*}$ & $0.954^{*}$ & - & - \\
\hline
\end{tabular}


ure thoracic rotation in seated position. The goniometer, bubble inclinometer, dual inclinometer, and smartphone clinometer measurements are reliable and valid nonradiologic measures of thoracic rotational ROM in lumbar locked posture in healthy adults. It indicates that all four devices can be used to measure thoracic rotation reliably by the same clinician and the measurement results of those devices were consistent between the examiners. The reliability of dual inclinometer and smartphone clinometer was highest among four devices. The reliability of smartphone clinometer is second highest in this comparison for both intraand inter-rater reliability. The value of thoracic rotation is at 47 degrees, but further study is required to confirm the standardized normal value for this measurement.

\section{Conflict of Interest}

The authors declared no potential conflicts of interest with respect to the authorship and/or publication of this article.

\section{References}

1. Nash CL Jr, Moe JH. A study of vertebral rotation. J Bone Joint Surg Am 1969;51:223-9.

2. White AA 3rd. Analysis of the mechanics of the thoracic spine in man. An experimental study of autopsy specimens. Acta Orthop Scand Suppl 1969;127:1-105.

3. Gregersen GG, Lucas DB. An in vivo study of the axial rotation of the human thoracolumbar spine. J Bone Joint Surg Am 1967;49:247-62.

4. Kebaetse M, McClure P, Pratt NA. Thoracic position effect on shoulder range of motion, strength, and three-dimensional scapular kinematics. Arch Phys Med Rehabil 1999;80:945-50.

5. Fernández-de-las-Peñas $C$, Palomeque-del-Cerro L, RodríguezBlanco C, Gómez-Conesa A, Miangolarra-Page JC. Changes in neck pain and active range of motion after a single thoracic spine manipulation in subjects presenting with mechanical neck pain: a case series. J Manipulative Physiol Ther 2007;30:312-20.

6. Theodoridis D, Ruston S. The effect of shoulder movements on thoracic spine 3D motion. Clin Biomech (Bristol, Avon) 2002; 17:418-21.

7. Fujimori T, Iwasaki M, Nagamoto Y, Ishii T, Kashii M, Murase $\mathrm{T}$, et al. Kinematics of the thoracic spine in trunk rotation: in vivo 3-dimensional analysis. Spine (Phila Pa 1976) 2012;37:E131828.

8. Willems JM, Jull GA, J KF. An in vivo study of the primary and coupled rotations of the thoracic spine. Clin Biomech (Bristol, Avon) 1996;11:311-6.
9. Chen J, Solinger AB, Poncet JF, Lantz CA. Meta-analysis of normative cervical motion. Spine (Phila Pa 1976) 1999;24:1571-8.

10. Dvorak J, Antinnes JA, Panjabi M, Loustalot D, Bonomo M. Age and gender related normal motion of the cervical spine. Spine (Phila Pa 1976) 1992;17(10 Suppl):S393-8.

11. Glaws KR, Juneau CM, Becker LC, Di Stasi SL, Hewett TE. Intra- and inter-rater reliability of the selective functional movement assessment (SFMA). Int J Sports Phys Ther 2014;9: 195-207.

12. Krzyzanowicz R, Baker R, Nasypany A, Gargano F, Seegmiller J. Patient outcomes utilizing the selective functional movement assessment and mulligan mobilizations with movement on recreational dancers with sacroiliac joint pain: a case series. Int $\mathrm{J}$ Athl Ther Train 2015;20:31-7.

13. Goshtigian GR, Swanson BT. Using the selective functional movement assessment and regional interdependence theory to guide treatment of an athlete with back pain: a case report. Int $\mathrm{J}$ Sports Phys Ther 2016;11:575-95.

14. Cook EG, Kiesel KB. Selective functional movement assessment. Physical Therapy Course Manual Edited. Danville, VA: Functional Movement; 2004.

15. Johnson KD, Kim KM, Yu BK, Saliba SA, Grindstaff TL. Reliability of thoracic spine rotation range-of-motion measurements in healthy adults. J Athl Train 2012;47:52-60.

16. Edmondston SJ, Aggerholm M, Elfving S, Flores N, Ng C, Smith $\mathrm{R}$, et al. Influence of posture on the range of axial rotation and coupled lateral flexion of the thoracic spine. J Manipulative Physiol Ther 2007;30:193-9.

17. Pearcy MJ, Tibrewal SB. Axial rotation and lateral bending in the normal lumbar spine measured by three-dimensional radiography. Spine (Phila Pa 1976) 1984;9:582-7.

18. Gajdosik RL, Bohannon RW. Clinical measurement of range of motion. Review of goniometry emphasizing reliability and validity. Phys Ther 1987;67:1867-72.

19. Rome K, Cowieson F. A reliability study of the universal goniometer, fluid goniometer, and electrogoniometer for the measurement of ankle dorsiflexion. Foot Ankle Int 1996;17:28-32.

20. Audette I, Dumas JP, Côté JN, De Serres SJ. Validity and between-day reliability of the cervical range of motion (CROM) device. J Orthop Sports Phys Ther 2010;40:318-23.

21. Nitschke JE, Nattrass CL, Disler PB, Chou MJ, Ooi KT. Reliability of the American Medical Association guides' model for measuring spinal range of motion. Its implication for wholeperson impairment rating. Spine (Phila Pa 1976) 1999;24:262-8.

22. Milani P, Coccetta CA, Rabini A, Sciarra T, Massazza G, Ferriero G. Mobile smartphone applications for body position measurement in rehabilitation: a review of goniometric tools. PM R 2014; 6:1038-43.

23. Shin SH, Ro du H, Lee OS, Oh JH, Kim SH. Within-day reliability of shoulder range of motion measurement with a smartphone. Man Ther 2012;17:298-304.

24. Charlton PC, Mentiplay BF, Pua YH, Clark RA. Reliability and concurrent validity of a Smartphone, bubble inclinometer and motion analysis system for measurement of hip joint range of motion. J Sci Med Sport 2015;18:262-7. 